\title{
Editorial
}

\section{Talk of the Town - Chikungunya}

Md. Rezwanur Rahman

Professor of Biochemistry

Delta Medical College, Dhaka, Bangladesh

In the city of Dhaka the mostly uttered disease in the last 3 to 4 months is most probably Chikungunya fever (pronunciation: chik-en-gun-ye). The capital city is facing an outbreak of this viral fever since April this year. It is borne by our old friend (enemy!) Aedes aegypti mosquito.

The term 'Chikungunya' often refers to both the virus (CHIKV) and the illness or fever (CHIKF) caused by this virus. Chikungunya fever is a self-remitting febrile viral illness that has been associated with frequent outbreaks in tropical countries of Africa and Southeast Asia. The first outbreak of Chikungunya was in a Swahili village of southern Tanzania in 1952. The name 'Chikungunya' derives from the African dialect Swahili or Kimakonde which means 'to become contorted or bent over'. In Congo, it is referred to as 'buka-buka', which means 'broken-broken'. These terms describe the stooped posture of the sufferers as a consequence of severe chronic incapacitating arthralgia. ${ }^{1,2}$

\section{Disease Outbreaks}

Chikungunya commonly occurs in Africa, Southeast Asia and the Indian subcontinent. For a number of years, human infections in Africa have been at relatively low levels but there was a large outbreak in the Democratic Republic of the Congo in 1999-2000, and another one in Gabon in 2007. ${ }^{1}$ Multiple outbreaks beyond West Africa have been described. In Asia, epidemics have been reported in India, Sri Lanka, Myanmar, Thailand, Indonesia, the Philippines, Cambodia, Vietnam, Hong Kong and Malaysia. ${ }^{3}$

Since 2004 chikungunya has spread widely, causing massive outbreaks with explosive onset in the Indian Ocean region, India and other parts of Asia. ${ }^{4,5}$ Institute of Epidemiology, Disease Control and Research (IEDCR) and International Centre for Diarrhoeal Disease Research, Bangladesh (ICDDR,B) conducted an investigation at Rajshahi and Chapianawabganj districts in December 2008 and reported the first outbreak of Chikungunya fever in Bangladesh, which was actually the third outbreak in our country. ${ }^{6}$ IEDCR noticed the presence of the disease in Dhaka later in 2011. ${ }^{7}$ In Dhaka there have been two episodes of outbreak in the last four months and it is already noticed that Chikungunya epidemics may have secular, cyclical and seasonal trends. Usually an inter-epidemic period of 4-8 years (sometimes as long as 20 years) is reported. Outbreaks are most likely to occur in the post-monsoon period when the vector density is very high. 3,8

\section{Disease Transmission}

Aedes aegypti is the main vector of transmission of Chikungunya in Bangladesh. Chikungunya virus maintains the human-mosquito-human transmission. The virus is transmitted from human to human by the bites of infected female mosquitoes, most commonly Aedes aegypti and Aedes albopictus. Incubation period is 4 to 12 days. ${ }^{1,9}$ The mosquitoes can be found biting throughout daylight hours. It can also been seen stinging in the early morning and late afternoon. ${ }^{10}$

\section{Symptoms}

Chikungunya should be suspected at epidemic outbreak of abrupt onset of fever $\left(>38.5^{\circ} \mathrm{C}\right)$, joint 
pain with or without skin rash. ${ }^{9}$ Most patients recover fully, but in some cases joint pain may persist for several months, or even years. $1,3,9$ Occasional cases of eye, neurological and heart complications have been reported, as well as gastrointestinal complaints. Often symptoms in infected individuals are mild and the infection may go unrecognized, or be misdiagnosed in areas where dengue occurs. ${ }^{1}$ People with hypertension, diabetes, ischaemic heart disease, cerebrovascular disease, old age, pregnancy, COPD or co-infection with dengue, tuberculosis, enteric fever, pneumonia, HIV, malaria are at great risk. ${ }^{9}$

\section{Criteria for the Identification of Chikungunya Infection}

According to the National Guideline on Clinical Management of Chikungunya Fever published by IEDCR, along with the usual symptoms i.e. the clinical criteria there are some epidemiological criteria for diagnosis like residing or having visited epidemic areas. Laboratory criteria includes at least one of the following tests in the acute phase: virus isolation by cell culture, presence of viral RNA by RT-PCR (within 5 days of onset of illness), presence of viral specific IgM antibody (within 5 to 28 days of onset), and four-fold rise of $\mathrm{IgG}$ antibody in samples collected at least three weeks apart (1st sample after 7 days). But diagnostic validity of currently available ICT kit for the detection of $\operatorname{IgM}$ and $\operatorname{IgG}$ for Chikungunya virus is very poor and RT-PCR for Chikungunya is performed only at IEDCR. ${ }^{11}$ But these tests do not change the course or treatment plan.

\section{Treatment}

There is no specific antiviral drug treatment for chikungunya. Treatment is primarily symptomatic with anti-pyretics, analgesics, non-steroidal anti inflammatory drugs and plenty of fluids. No vaccine is available till date..$^{1,12}$

\section{Prevention and Control}

As of other viral infections spread by mosquito our main tool against them are prevention. Prevention and control primarily depends on reducing the number of natural and artificial water-filled container habitats that support breeding of the mosquitoes. During outbreaks, insecticides may be sprayed, applied to surfaces in and around breeding places and repellents can be applied to exposed skin or to clothing. Insecticide-treated mosquito nets, mosquito coils or other insecticide vaporizers may also reduce indoor biting. ${ }^{1}$

The government has been working with WHO and other agencies to fight the spread of virus by conducting awareness campaigns, rally and seminars throughout the capital and other cities. IEDCR advises removal of all open containers with stagnant water in and around the houses like flower plates and pots, used tires, tree holes and rock pools on a regular basis. The IEDCR advises patients to take rest under bed-nets, preferably permethrin-impregnated nets. ${ }^{7}$ It is all of our duty to be more conscious and responsible to prevent disease spread.

Inspite of being aware and alert the disease is still spreading fast and experts from ICDDR,B have warned that it may continue till September i.e. end of monsoon. ${ }^{13}$ IEDCR has identified 21 areas in Dhaka city as most risky for Chikungunya and it has spread to at least four more districts of Bangladesh with hundreds of confirmed cases. ${ }^{14,15}$

Delta Med Col J. Jul 2017;5(2):54 - 56

\section{References}

1. WHO [Internet]. Chikungunya Fact Sheet. 2017 April (cited 2017 June 25). Available from: http://www.who.int/mediacentre/factsheets/ fs $327 / \mathrm{en} /$.

2. Natesan SK, Chandrasekar PH. Chikungunya Virus. Medscape [Internet]. 2016 Oct 27 (cited 2017 June 25). Available from: http://emedicine.medscape. com/article/2225687-overview.

3. Hoque MS, Ahmed ANU. Chikungunya Fever and Bangladesh: Review and Updates. DS (Child) H J. 2012;28(2):115-22. 
4. Charrel RN, de Lamballerie X, Raoult D. Chikungunya Outbreaks - the Globalization of Vector Borne Diseases. N Engl J Med. 2007;356:769.

5. Mavalankar D, Shastri P, Raman P. Chikungunya Epidemic in India: a Major Public Health Disaster. Lancet Infect Dis. 2007;7:306.

6. Hassan R, Rahman MM, Moniruzzaman M, Rahim A, Barua S, Biswas R, et al. Chikungunya - an Emerging Infection in Bangladesh: a Case Series. J Med Case Rep. 2014;8:67.

7. bdnews24.com [Internet]. Hasib NI. Chikungunya Viral Disease Spreads Fast in Dhaka. 2017 May 16 (cited 2017 June 25). Available from: http://bdnews24.com/health/2017/05/16/chikunguny a-viral-disease-spreads-fast-in-dhaka .

8. Don't Panic Over Chikungunya: Doctors. Star Online Report [Internet]. 2017 May 18 (cited 2017 June 25). Available from: http://www.thedailystar. net/health/dont-panic-over-mosquito-borne-viral-ou tbreak-chikungunya-doctors-dhaka-bangladesh-140 7103.

9. Pedimedicine [Internet]. Hossain A. Chikungunya Virus in Bangladesh National Guideline. 2017 July 18 (cited 2017 July 22). Available from: http://pedimedicine.com/mosquito-disease-chikung unya-fever-symptoms-diagnosis-treatment/.
10. Islam T. Chikungunya: How to be Cured of It? [Internet]. 2017 May 21 (cited 2017 June 25). Available from: http://en.prothom-alo.com/ bangladesh/news/148735/Chikungunya-How-to-becured-of-it.

11. National Guideline on Clinical Management of Chikungunya Fever. Disease Control unit (CDC), Directorate General of Health Services (DGHS), Bangladesh; 2017.

12. Bettadapura J, Herrero LJ, Taylor A, Mahalingam S. Approaches to the Treatment of Disease Induced by Chikungunya Virus. Indian J Med Res. 2013;138(5):762-65.

13. Chikungunya Likely to Stay till Sep [Internet]. 2017 Jun 15 (cited 2017 June 25). Available from: http://en.prothom-alo.com/bangladesh/news/151203 /Chikungunya-likely-to-stay-till-Sep.

14. 21 Areas in Dhaka City Most Risky for Chikungunya [Internet]. 2017 June 10 (cited 2017 June 25). Available from: http://www.thedailystar.net/health/ 21-areas-dhaka-city-most-risky-chikungunya-report -1417462 .

15. www.benarnews.org [Internet]. Chowdhury KR. Chikungunya Outbreak Spreads beyond Bangladeshi Capital: Health Officials. 2017 July 21 (cited 2017 July 22). Available from: http://www.benarnews. org/english/news/bengali/bangladesh-health-072120 17170830.html. 